\title{
Simulating the yields of bioenergy and food crops with the crop modeling software BioSTAR: the carbon-based growth engine and the BioSTAR ET 0 method
}

\author{
Roland Bauböck
}

\begin{abstract}
Background: With a growing production and use of agricultural substrates in biogas facilities, the competition between food and energy production, environmental issues, and sustainability goals has seen an increase in the last decade and poses a challenge to policy makers. Statistical yield data has a low spatial resolution and only covers standard crops and makes no statement in regard to yields under climate change. To support policy makers and regional planners in an improved allocation of agricultural land use, a new crop model (BioSTAR) has been developed.

Results: Simulations with weather and yield data from 7 years and four regions in Lower Saxony have rendered overall good modeling results with prediction errors (RMSE and percentage) ranging from $1.6 \mathrm{t}$ and $9.8 \%$ for winter wheat to $2.1 \mathrm{t}$ and $11.9 \%$ for maize. The model-generated $\mathrm{ET}_{0}$ and $\mathrm{ET}_{\mathrm{a}}$ values (mean of four locations) are lower than $\mathrm{ET}_{0} / \mathrm{ET}_{\mathrm{a}}$ values calculated with the Penman-Monteith method but appear more realistic when compared to field trial data from northern and eastern Germany.

Conclusions: The model has proven to be a functioning tool for modeling site-specific biomass potentials at the farm level, and because of its Access ${ }^{\oplus}$ database interface, the model can also be used for calculating biomass yields of larger areas, like administration districts or states. Out of the seven crops modeled in this study, only limited yield and test site data was available for winter barley, winter rye, sorghum, and sunflower. For further improvement of model performance and model calibration, more trial data and data testing are required for these crops.
\end{abstract}

Keywords: Crop modeling; Energy crops; BioSTAR; Biomass potentials; Evapotranspiration modeling

\section{Background}

The demand for biomass from agricultural resources as an energy source is currently seeing a strong increase. This is particularly true for Germany, as the country is trying to double the share of bioenergy (agricultural, forest, and waste biomass combined) to the country's energy total by the year 2020 [1].

In 2011, 2.2 million ha of the total agricultural area (17 million ha) was already in use for either energy crop production or renewable primary products. Of this area, 800,000 ha was in use for biogas crops, mainly maize,

Correspondence: rbauboe1@gwdg.de

Department of Cartography, GIS and Remote Sensing, Research Project 'BIS', University of Göttingen, Goldschmidtstraße 5, Göttingen 37077, Germany
900,000 ha for oilseed rape (mainly for biodiesel production) and, the smallest share, 250,000 ha for starch and bioethanol production. By 2020, the agricultural area in use for renewable resource production in Germany is projected to be further expanded and will then have a share of around $20 \%$ of the country's total agricultural area. Even though Germany's food production is close to self-sufficient today, a growing competition between food production, environmental issues, sustainability goals, and the production of energy and renewable primary products is moving into the focus of policy makers and researchers. At present, the production of biogas from energy crops and agricultural wastes (manure and other residual materials) appears to be the most (land 
resource) efficient way to use agricultural areas for energy production. This is due to the relatively high energy yield of biogas per hectare [2]. This advantage of biogas is even higher when power-heat cogeneration technology is applied.

In an intensively used agricultural landscape, as it is the case in Germany, good management and farming practices and diverse crop rotation cycles are of importance, and the introduction of new energy crops into the existing crop rotation cycles can be beneficial for ecological reasons $[3,4]$. One research project working on this interdisciplinary topic is the currently running bioenergy project of the University of Göttingen [5].

On the contrary, using mainly maize as a substrate in biogas facilities can lead to monocultures, soil erosion, and nitrate problems in the drinking water. This is even exacerbated in areas where a lot of maize is already grown for animal feed as is the case in the western part of Lower Saxony.

Using a crop modeling tool, yield differences of different crop rotations and crops can be approximated and optimized solutions, with economical as well as ecological perspectives in view, can be found out.

Crop models have been in existence for about four decades now [6]. Resource capture of an agricultural crop can be implemented in a model in different ways. Commonly used approaches are either carbon-based [7], radiation use efficiency (RUE)-based [8], water productivitybased (WP) [9], or transpiration-based (BTR) [10].

BioSTAR's primary growth engine is carbon-based, and it uses an asymptotic exponential light response curve [11]. Among the well-known crop models, the RUE approach is probably the one which is most often used. Examples for crop models with this type of growth engine are CropSyst [12], APSIM [13], CERES (DSSAT) [14], and LINTUL. Carbon-based growth engines are used in all of the older models from Wageningen such as WOFOST and in the model CROPGRO (DSSAT).

The water productivity approach is relatively new [15], and it has been implemented in the model AquaCrop [16]. The transpiration-based growth engine (BTR) is used as a second growth engine in the model CropSyst. Because the Tanner-Sinclair relationship becomes unstable at low VPD, the RUE method is used as a main growth engine in the model CropSyst.

Even though there are numerous crop models in existence today, no single model can claim to adequately cover all possible demands a user might put to such a model. One big advantage of developing a new model is the ability to structure and build the model according to user specifications and to be able to modify it and add on to it to suit future demands.

The crop model Biomass Simulation Tool for Agricultural Resources (BioSTAR) [17,18] has been developed to simulate climate and soil-dependent biomass yields for bioenergy crops, but obviously it can also be used to predict yields for food crops like wheat or rye. The model's software is built in such a way that, depending on the resolution of the input data, large-scale (single plots or farms) or small-scale (larger areas with many input datasets) yield predictions can be generated very easily. Novelties in the BioSTAR crop modeling software are a MS Access $^{\oplus}$ database connection for fast data editing and organization and the possibility to choose between four different growth engines and four $\mathrm{ET}_{0}$ methods. Validation runs for several agricultural crops grown in Lower Saxony have proven the models' capability to serve as a user-friendly biomass simulation tool for small- and large-scale agricultural planning.

\section{Results and discussion Biomass yields}

To validate the model BioSTAR, yield, soil, and climate data from five different locations in Lower Saxony, Germany have been used. The first two locations are farm plots in Hedeper and in Troegen. The other two are field trial sites of the Chamber of Agriculture of Lower Saxony (LWK), situated in Poppenburg and in Werlte. Winter wheat and maize were grown at all four localities, sunflower, sorghum, winter rye, and winter barley only in Poppenburg and Werlte, and sugar beet only in Hedeper.

The overall simulation results (all have been performed with the carbon-based growth engine and the BioSTAR $\mathrm{ET}_{0}$ method) have shown that the model predicts biomass yields at a good level of accuracy, though differences between cultures exist (Table 1). For the culture sugar beet (in the following referred to as beet), the analysis has been divided up into three parts: (1) all soil types, (2) clay soil types, and (3) no clay soils. This has been done to distinguish the unique reaction (overestimation) of beet to soils with high clay contents. The model produced the lowest error values (root-meansquare error (RMSE) and percentage error) for winter wheat $(\mathrm{RMSE}=1.6 \mathrm{t}$ and $10.1 \%)$, sorghum $(\mathrm{RMSE}=1.0 \mathrm{t}$ and $5.9 \%$ ), winter barley (RMSE $=1.8 \mathrm{t}$ and $11.0 \%$ ), winter rye $(\mathrm{RMSE}=1.9 \mathrm{t}$ and $10.4 \%$ ). Beet (clay), beet (no clay), and beet (all) simulation results show up with errors of $10.7 \%, 10.8 \%$, and $11.4 \%$, respectively, and an RMSE of $1.7 \mathrm{t}$ on clay and $2.4 \mathrm{t}$ for the other two. Sunflower and maize results show errors of $12.0 \%$ and $11.9 \%$ and RMSE values of 1.6 and $2.1 \mathrm{t}$, respectively. All crops combined in one analysis show up with mid-range error values (RMSE $2.1 \mathrm{t}$ and 12.2\%). The percentage error values have been calculated by dividing the RMSE by the mean observed yield (both are in tons per hectare).

Looking at the other statistical measure for model prediction accuracy, the Willmott index of agreement, the 
Table 1 Mean for observed and simulated yields, RMSE, percentage error, and WIA for tested crops

\begin{tabular}{|c|c|c|c|c|c|c|}
\hline & Mean observed & Mean simulated & RMSE & Number & Percentage error & WIA \\
\hline Maize & 17.7 & 18.2 & 2.1 & 31 & 11.9 & 0.94 \\
\hline Winter wheat & 15.8 & 16.1 & 1.6 & 102 & 10.1 & 0.86 \\
\hline Beet (all) & 21.0 & 21.8 & 2.4 & 40 & 11.4 & 0.77 \\
\hline Beet (clay) & 15.9 & 21.1 & 1.7 & 8 & 10.7 & 0.94 \\
\hline Beet (no clay) & 22.3 & 21.9 & 2.4 & 32 & 10.8 & 0.85 \\
\hline Winter barley & 16.3 & 16.1 & 1.8 & 6 & 11.0 & 0.64 \\
\hline Winter rye & 18.3 & 18.7 & 1.9 & 6 & 10.4 & 0.73 \\
\hline Sunflower & 13.3 & 13.4 & 1.6 & 9 & 12.0 & 0.56 \\
\hline Sorghum & 17.0 & 17.3 & 1.0 & 5 & 5.9 & 0.78 \\
\hline All crops & 17.2 & 17.7 & 2.1 & 198 & 12.2 & 0.92 \\
\hline
\end{tabular}

WIA, Willmott index of agreement ( $1=$ perfect agreement, $0=$ no agreement). Mean observed, mean simulated, and RMSE (root-mean-square error) given in tones dry mass per hectare.

resulting order of the crops is a different one. Now maize and beet (clay) are ranked first, both with a WIA of 0.94 followed by winter wheat (0.86), beet (no clay) (0.85), and sorghum (0.78). The lower ranks are now occupied by beet (all) (0.77), winter rye (0.73), winter barley (0.64), and sunflower (0.56). All crops combined in one analysis have achieved a high WIA of 0.92 .

The low WIA values for the winter grains (other than winter wheat) can be explained by an approximately equal over- and underestimation of the observed results (and possibly a low number of samples), whereas the predicted biomass for beet on clay type soils is exclusively overestimated at a similar level (Figure 1). Sorghum yields have been calculated well for the years 2008/2009 but were then overestimated at a high level in 2010 (Figure 2). Sunflower's biomass yield is predicted well in 4 years and then overestimated highly in 2007 (Figure 3). To some extent, this could be the result of a fungus infection (Sclerotinia sclerotiorum) which has reportedly [19] damaged the sunflower crops in the extremely rainy summer of 2007.

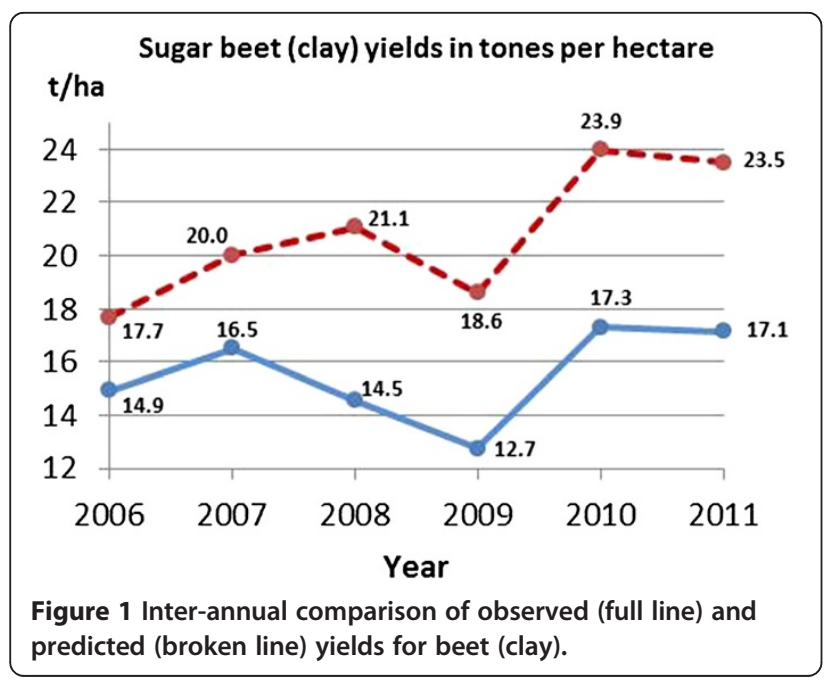

The overall reaction of the model in response to interannual climatic variations is at a good level of accuracy with the curves of the predicted vs. the observed biomass yields following the same pattern (Figure 4). This is particularly true for maize (Figure 5), winter barley and winter rye (Figure 6), winter wheat (Figure 7), and sugar beet (no clay) (Figure 8). The corresponding curves of beet (clay), beet (all) (Figures 1 and 9), sorghum (Figure 2), and sunflower (Figure 3) display some deviations from the inter-annual trend.

For all crops combined in one analysis, a linear regression analysis has been performed. The $R^{2}$ value $(0.71)$ for the whole dataset (observed vs. predicted yields) is at a satisfactory level (Figure 10) and has a high correlation (Pearson correlation coefficient of 0.845 at a highly significant level of $\alpha \leq 0.01$ ).

\section{Evapotranspiration levels}

Unlike other crop models, BioSTAR can generate its own crop and phenology-dependent potential transpiration

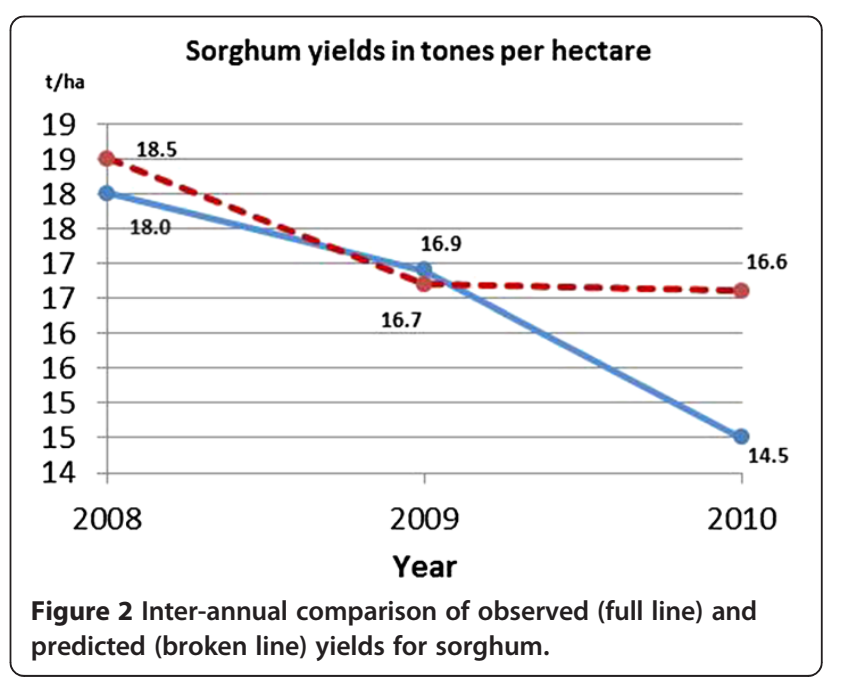




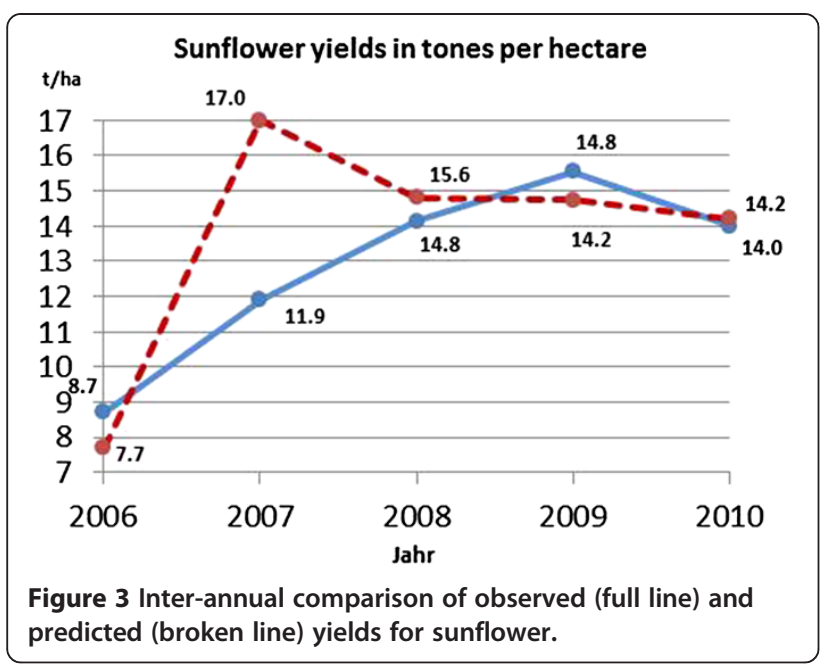

rates (see 'Main model processes') to which a leaf areadependent soil evaporation value is added. In Figure 11, the mean values of all four locations of the simulation and all 7 years of the BioSTAR ET $\mathrm{ET}_{0}$ (potential evapotranspiration) and $\mathrm{ET}_{\mathrm{a}}$ (actual evapotranspiration) method are displayed along with the corresponding Food and Agriculture Organization (FAO) (Penman-Monteith) values calculated for these years. For both calculations a maize crop with a cropping period from the end of April until the beginning of September was chosen. $\mathrm{ET}_{0}$ values calculated with the BioSTAR method are considerably lower than their FAO method equivalents. To a lesser extent, this is also true, when the $\mathrm{ET}_{\mathrm{a}}$ values of the two methods are compared. The BioSTAR $\mathrm{ET}_{0}$ and $\mathrm{ET}_{\mathrm{a}}$ values range from $543 \mathrm{~mm} \mathrm{(2008)} \mathrm{to} 430 \mathrm{~mm} \mathrm{(2007)}$ and from $423 \mathrm{~mm}$ (2007) to $349 \mathrm{~mm}$ (2012), respectively. The FAO curves for $\mathrm{ET}_{0}$ and $\mathrm{ET}_{\mathrm{a}}$ follow a similar inter-annual trend but at levels which are approximately $200 \mathrm{~mm}\left(\mathrm{ET}_{0}\right)$ and $50 \mathrm{~mm}$ $\left(\mathrm{ET}_{\mathrm{a}}\right)$ above the BioSTAR values. The high $\mathrm{ET}_{0}$ values of



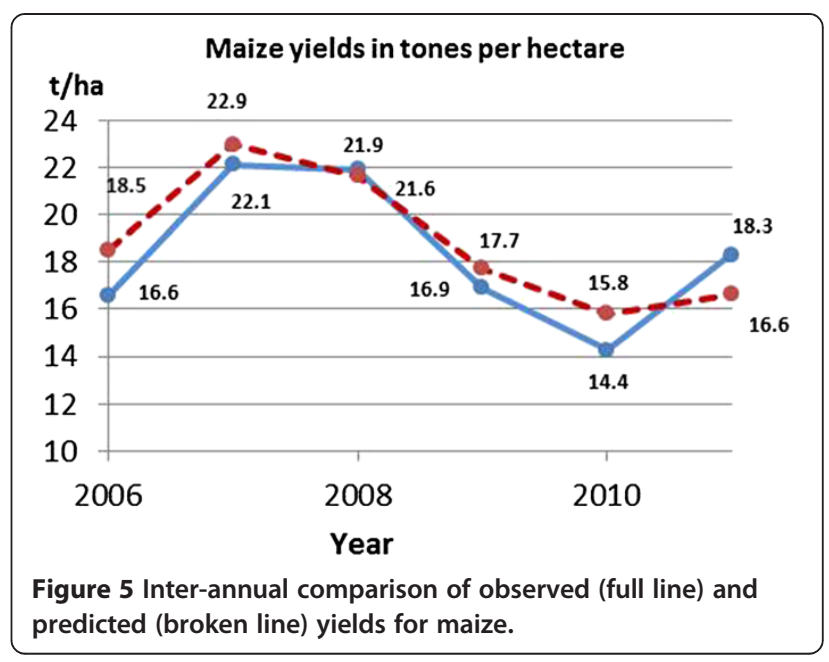

the FAO calculation can be explained by the fact that no crop or phenology parameters have been considered here (grass reference evapotranspiration). Looking at the literature data for $\mathrm{ET}_{\mathrm{a}}$ values for northern and eastern Germany, the FAO values appear to be overestimated. Haferkorn [20] and Zenker [21] give $\mathrm{ET}_{\mathrm{a}}$ values for various crops measured by lysimeters in eastern Germany, ranging from 280 to $530 \mathrm{~mm}$ (April until September), with average values around $350 \mathrm{~mm}$. The DVWK [22] estimates the share of the evapotranspiration from May until September to be about $70 \%$ of the year's total precipitation. Since Germany's climate is of a humid character and average annual precipitation values range between 600 and $800 \mathrm{~mm}$, annual evapotranspiration for this climate is not likely to be higher than $600 \mathrm{~mm}$. In fact the DVWK gives an average annual evapotranspiration value $\left(\mathrm{ET}_{\mathrm{a}}\right)$ of $433 \mathrm{~mm}$ for northern Germany. Eulenstein et al. [23] give annual $\mathrm{ET}_{0}$ values for eastern Germany for the years 1971 to 1998 ranging from 420 to $680 \mathrm{~mm}$ (the approximate mean is

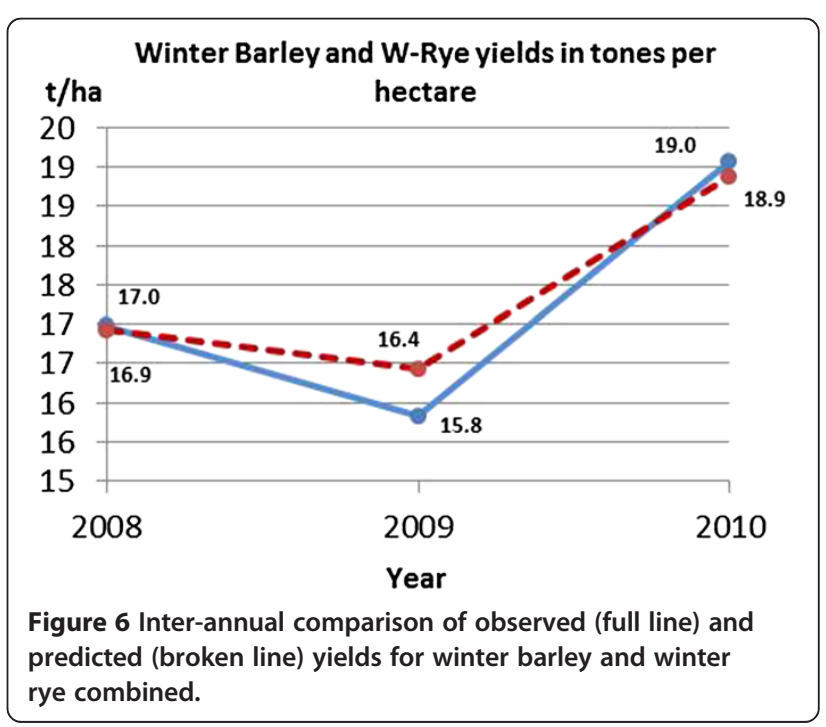




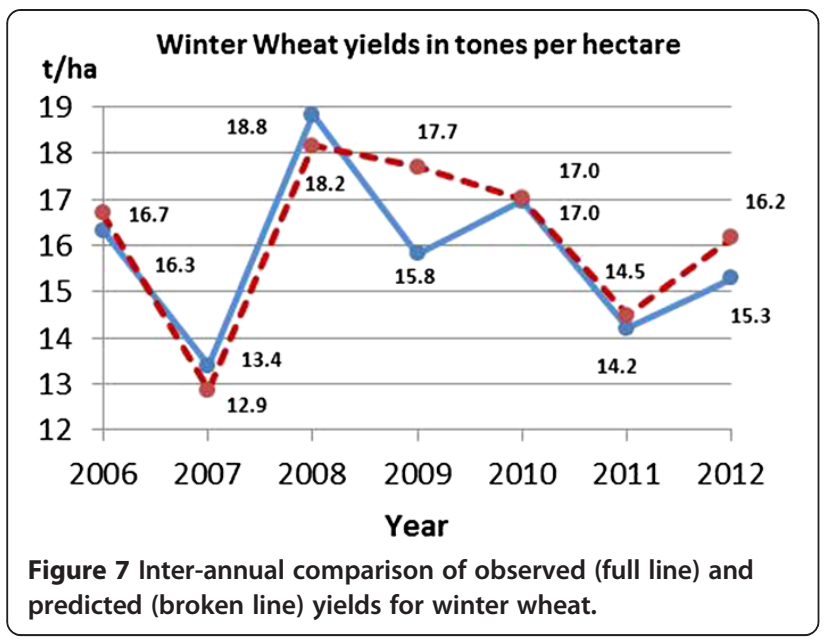

around $570 \mathrm{~mm}$ ). Additionally it needs to be mentioned that eastern Germany has a more arid and continental climate than Lower Saxony.

In comparison with this data, the BioSTAR $\mathrm{ET}_{0}$ and $\mathrm{ET}_{\mathrm{a}}$ values seem to be more realistic than the FAO values and underline the relevance of this ET method for the computation of crop biomass potentials.

\section{Conclusions}

The performance of the crop model BioSTAR has been tested with datasets from four locations in Lower Saxony, Germany for seven agricultural crops. The model predicts biomass yields for all crops combined at a satisfactory level (mean error of $12.1 \%$ ). The yields of all crops have been predicted by the model with errors ranging from $8.4 \%$ (winter wheat) to $12.1 \%$ (maize). The model has proven to be a functioning tool for modeling site-specific biomass potentials at the farm level. Because of its Access $^{\ominus}$ database interface, the model can also



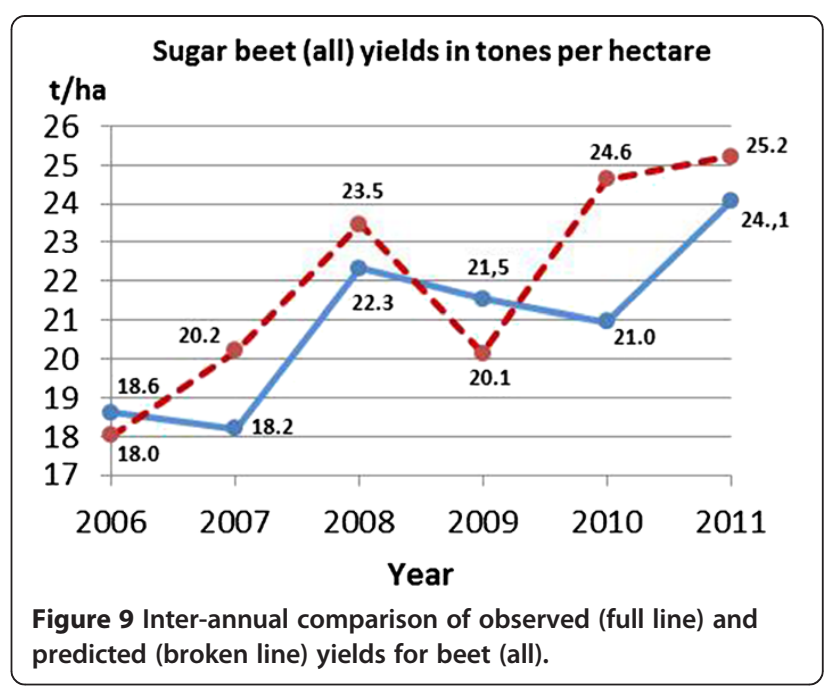

easily be used for the prediction of potential biomass yields of larger areas, like administration districts or states and can therefore serve as a decision support tool when questions of regional and trans-regional crop planning are concerned. Because the model reacts adequately to inter-annual climatic differences, transferability to different climates is probably possible but still needs to be validated. BioSTAR offers its own method for calculating evapotranspiration during the course of crop growth. The model-generated evapotranspiration levels are lower than the ones calculated using the Penman-Monteith approach but seem to be closer to actually measured ET values in northern and eastern Germany.

Out of the seven crops modeled in this study, only limited yield and test site data was available for winter barley, winter rye, sorghum, and sunflower. For further improvement of model performance and model calibration, more trial data and data testing are required here.

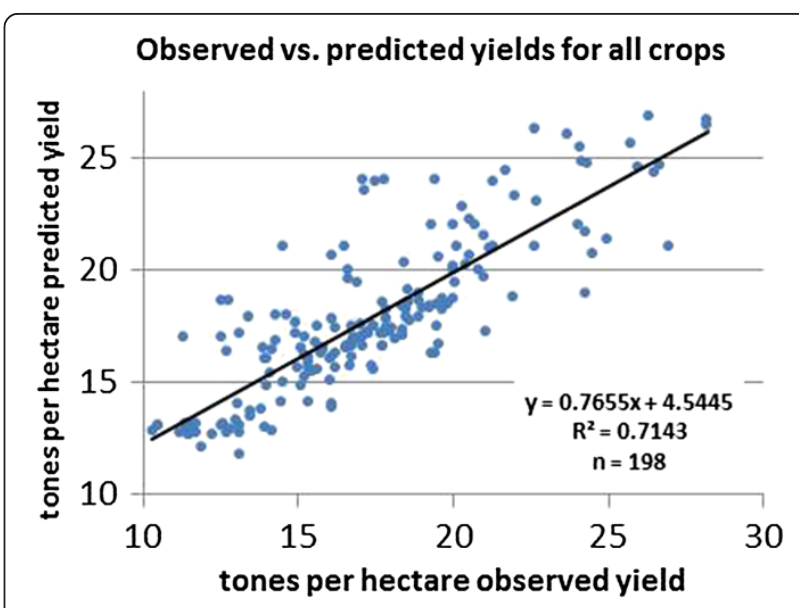

Figure 10 Linear regression analysis of observed vs. predicted yields for all crops. 


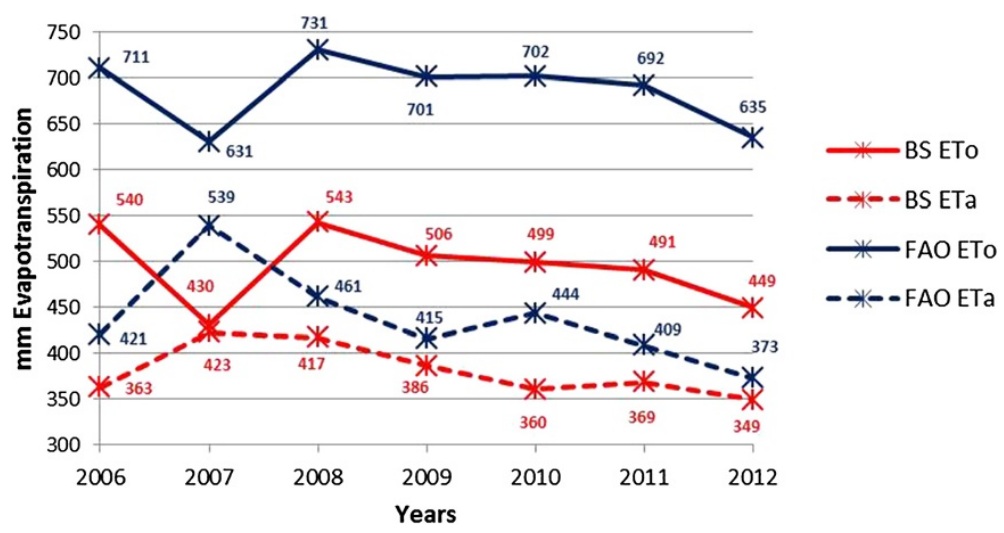

Figure 11 Inter-annual comparison of $\mathrm{ET}_{0}$ and $\mathrm{ET}_{\mathrm{a}}$ values calculated with the BioSTAR and FAO (Penman-Monteith) methods.

The reaction of the sugar beet yield development on clay-type soils still needs to be investigated further and improved in the model. Up to date (September 2013), the model is capable of simulating the general reaction of crops to water and nitrogen stress. To further expand the models' range of application, soil salinity content and related salinity stress reaction of plants should be implemented in the model.

Grasses and perennial cultures like the cup plant (Silphium perfoliatum) or short rotation coppices like poplar or willow are potential cultures for bioenergy production in the German agricultural sector. Up to date (September 2013), the model BioSTAR is capable of modeling these cultures, but calibration and validation still have to be performed before the model can be used for yield prediction of these cultures.

\section{Methods}

\section{Main model processes}

BioSTAR's primary growth engine is carbon-based (see above) and calculates a radiation and temperaturedependent gross $\mathrm{CO}_{2}$ exchange rate in $\mathrm{mmol} \mathrm{CO}_{2} \mathrm{~m}^{-2} \mathrm{~s}^{-1}$ (Equation 1).

Photorespiration (maintenance and growth) and nitrogeninduced photosynthesis inhibition are accounted for in a second step. The remaining fraction of $\mathrm{CO}_{2}$ (net photosynthesis) is then used to calculate a net photosynthesis-dependent transpiration rate. This is done using the gradients of the water vapor pressure and of the $\mathrm{CO}_{2}$ concentration inside the leaves to the corresponding pressures of the atmosphere (Equations 2 to 5). Due to this calculation procedure, BioSTAR does not need a separate $\mathrm{ET}_{0}$ calculation (e.g., Penman, FAO, Turc, or other) to compute crop transpiration (Figure 12):

$$
P_{\mathrm{G}}=P_{\max } \times 1-\exp ^{\left(-\mathrm{Q} \times \mathrm{PPFDI} / P_{\max }\right)},
$$

where $P_{\mathrm{G}}$ is the gross photosynthesis rate $\left(\mathrm{mmol} \mathrm{CO}_{2}\right.$ $\left.\mathrm{m}^{-2} \mathrm{~s}^{-1}\right)$, Qe is the initial light use efficiency $(\mathrm{mmol} \mathrm{CO}$ $\mathrm{mol}^{-1}$ light quantum), PPFDI is the intercepted photosynthetic active radiation $\left(\mathrm{mmol} \mathrm{m} \mathrm{m}^{-2} \mathrm{~s}^{-1}\right)$, and $P_{\max }$ is the maximum photosynthesis rate $\left(\mathrm{mmol} \mathrm{CO}_{2} \mathrm{~m}^{-2} \mathrm{~s}^{-1}\right)$.

$$
\begin{aligned}
\mathrm{H}_{2} \mathrm{O}_{\text {grad }}: & \left(\left(\mathrm{VP}_{\text {def }} \times \mathrm{Vol}_{\text {mol }}\right) / 18\right) \times 1,000 \\
\mathrm{CO}_{2 \text { grad }}: & \left(\mathrm{CO}_{2 \text { con }}-\left(\mathrm{CO}_{2 \text { con }} \times C_{\mathrm{i}} / C_{\mathrm{a}}\right)\right) / 1,000 \\
\text { Wat }_{\text {use }}: & \left(\mathrm{H}_{2} \mathrm{O}_{\text {grad }} / \mathrm{CO}_{2 \text { grad }}\right) \times 1.56 \\
\text { Transpot : } & \left(P_{\text {rate }} \times 3.6 \times L_{\text {day }} \times 44 \times 1,000\right) \\
& \times \text { Wat }_{\text {use }} \\
\text { Evapleaf : } & \left\{\left(1-\left(\operatorname{Resist}_{\mathrm{A}} / 250\right)\right) \times 0.25\right\}+1 \\
P_{\text {reduct }}: & P_{\text {net }} \times\left(\mathrm{ET}_{\mathrm{a}} / \mathrm{ET}_{0}\right) \times S_{\text {reduct }},
\end{aligned}
$$

where $\mathrm{H}_{2} \mathrm{O}_{\text {grad }}$ is the $\mathrm{H}_{2} \mathrm{O}$ gradient from leaf to atmosphere $\left(\mathrm{mmol} \mathrm{mol}^{-1}\right), \mathrm{VP}_{\text {def }}$ is the vapor pressure deficit of the air $\left(\mathrm{g} \mathrm{m}^{-3}\right), \mathrm{Vol}_{\text {mol }}$ is the volume of $1 \mathrm{~mol}$ dry air, $\mathrm{CO}_{2 \text { grad }}$ is the $\mathrm{CO}_{2}$ gradient from leaf to atmosphere $\left(\mathrm{mmol} \mathrm{mol}^{-1}\right), \mathrm{CO}_{2 \mathrm{con}}$ is the $\mathrm{CO}_{2}$ concentration of the atmosphere (ppm), $C_{\mathrm{i}} / C_{\mathrm{a}}$ is the internal-external $\mathrm{CO}_{2}$ ratio dimensionless, range approximately 0.1 to 1.0 , Wat use $_{\text {us }}$ is the $\mathrm{H}_{2} \mathrm{O}-\mathrm{CO}_{2}$ evolution ratio dimensionless, Transpot is the $\mathrm{CO}_{2}$ assimilation-dependent potential transpiration rate $\left(\mathrm{L}\right.$ day $\left.^{-1}\right), P_{\text {rate }}$ is the $\mathrm{CO}_{2}$ assimilation rate $\left(\mathrm{mmol} \mathrm{CO} \mathrm{C}^{-2} \mathrm{~s}^{-1}\right), L_{\text {day }}$ is the daylight hours, Evapleaf is the aerodynamic resistance-dependent multiplier for leaf evaporation, Resist $_{\mathrm{A}}$ is the aerodynamic resistance $\left(\mathrm{s} \mathrm{m}^{-1}\right), P_{\text {reduct }}$ is the stomata conductance-induced photosynthesis reduction $\left(\mathrm{g} \mathrm{day}^{-1}\right), P_{\text {net }}$ net photosynthesis (after respiration and nitrogen-induced reduction) $\left(\mathrm{g} \mathrm{day}^{-1}\right.$ ), and $S_{\text {reduct }}$ is the function for water stressinduced photosynthesis reduction.

The transpiration rate calculated by Equation 5 is multiplied by a dimensionless factor (Evapleaf) to account for aerodynamic resistance and leaf evaporation 


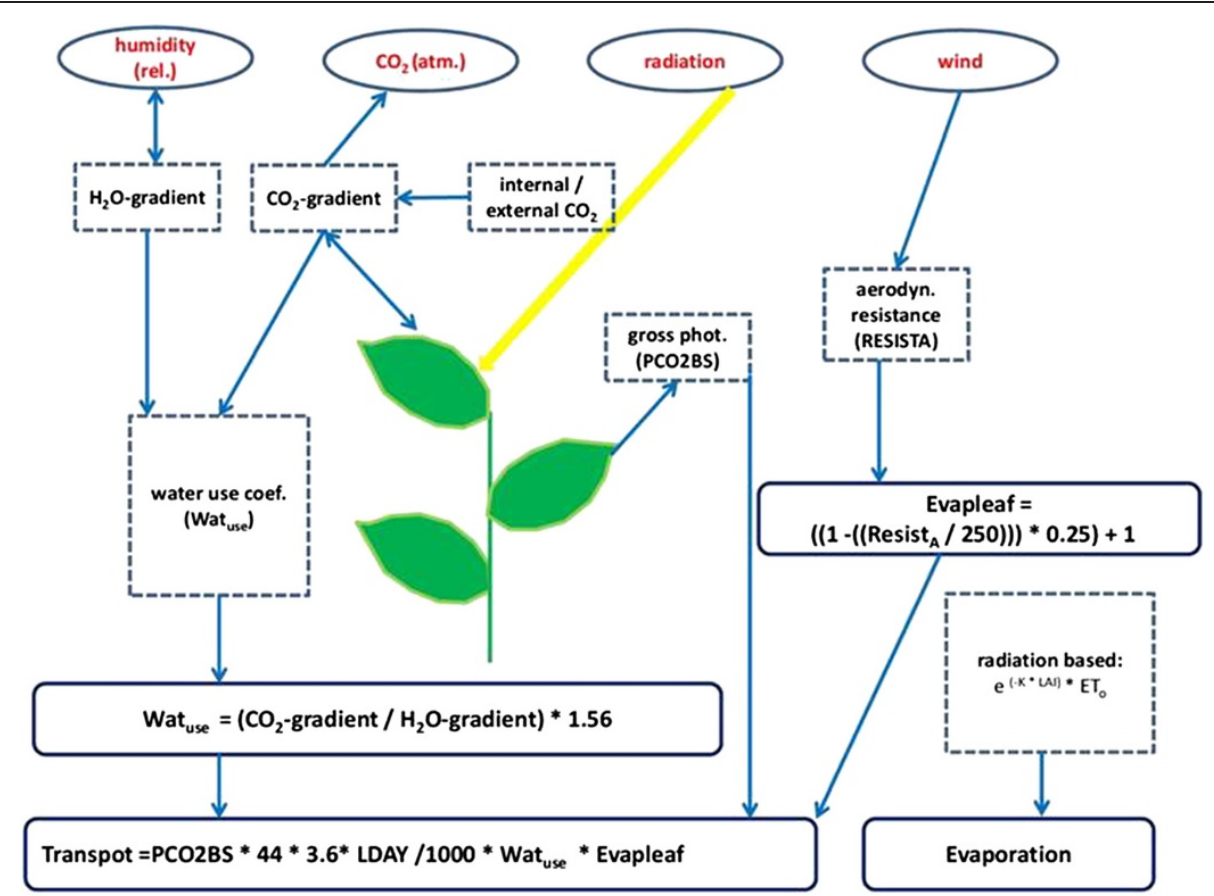

Figure 12 BioSTAR method of transpiration calculation.

(Equation 6) and then added to a leaf area-dependent soil evaporation value. The resulting evapotranspiration value $\left(\mathrm{ET}_{0}\right)$ is then used in the soil sub-model to check if enough water for evapotranspiration is available in the rooted layers of the soil profile. Soil water availability is defined by each layer's individual soil water retention curve. If the available soil water, available for evapotranspiration $\left(\mathrm{ET}_{\mathrm{a}}\right)$, is smaller than the calculated $\mathrm{ET}_{0}$, biomass accumulation is lowered correspondingly (Equation 7).

Crop development and leaf area index (LAI) development are temperature driven and divided into two main stages: emergence until anthesis (development stages 0 to 1 ) and anthesis until ripeness (development stages 1 to 2). Maximum LAI is reached at development stage 1, and the curve of LAI development is modeled as a Gaussian integral (normal distribution).

\section{Software architecture and model features}

The BioSTAR software is written in Java and uses a connection to Microsoft Access ${ }^{\oplus}$ database tables to read input data and write output data (Figure 13 and Table 2).

Data can easily be imported into these tables from spreadsheets like Excel ${ }^{\circ}$, and output data can be exported to a GIS for spatial visualization via the dbf format. One advantage of this software architecture is that all relevant data for running simulations is stored in one Access $^{\oplus}$ database which contains different tables storing location, weather, crop, and soil texture variables. For each simulation run (combination of location and weather data), a new result table is generated in the database. Because all parameters (for crops and soil) are stored in the same database file, editing and comparison of the contents is easily done. Running the model on a $\mathrm{PC}$ or laptop requires an installed version of Microsoft Access $^{\oplus}$ (versions 2007 or later) and the installation of Java runtime environment (freeware). The model software itself is contained in an executable JAR file and does not need to be installed on the computer.

\section{Model calibration and input data}

The model has been calibrated and tested for different sites and years in Lower Saxony for the winter cereals wheat, rye, triticale, and barley, for maize, sorghum, and sugar beet, and for sunflower. Further cultures which have been implemented in the model are canola (oilseed rape), cup plant (S. perfoliatum), and the short rotation coppices poplar and willow, although no validation for these cultures has been performed so far.

For model calibration, harvest and weather data (5 years) and soil data from two locations (Poppenburg and Werlte) in Lower Saxony has been used (Table 1). At these two locations, regular field trials are carried out by the LWK (Chamber of Agriculture Lower Saxony). For further testing of the model, additional harvest and weather data (7 years) from two farms in Lower Saxony (Hedeper and Trögen) were used. Soil qualities at these four locations cover a wide range from deep silt and silt loams to more shallow sands and sand loams and clays. Model testing has been performed for maize, winter wheat, winter barley, winter rye, sugar beet sunflower, 


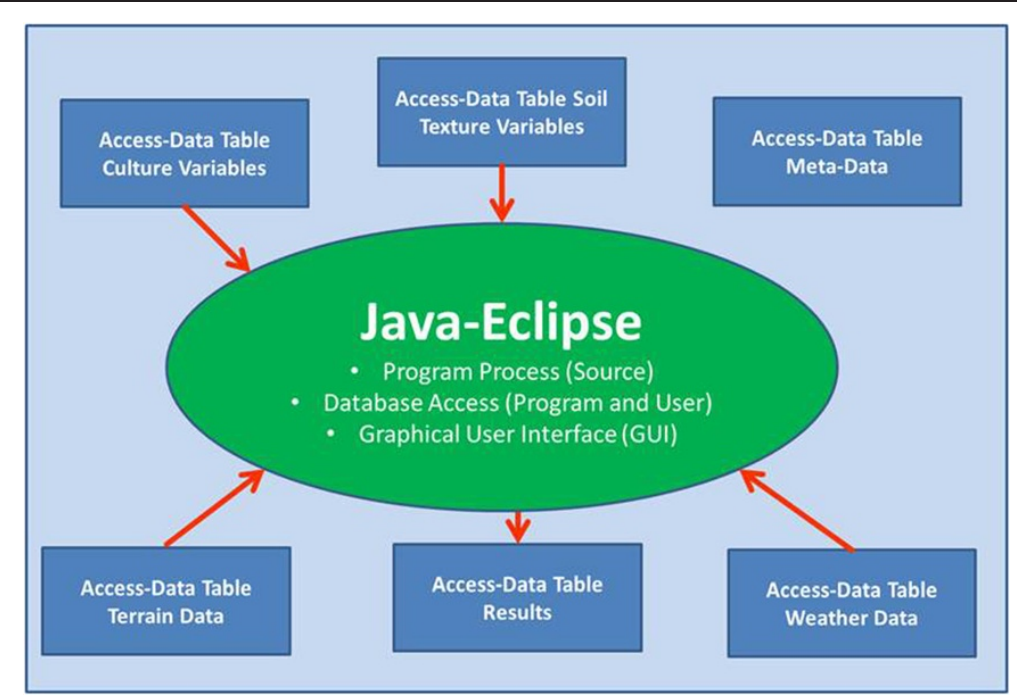

Figure 13 Software architecture of the BioSTAR model.

and sorghum. The growth engine and $\mathrm{ET}_{0}$ method settings used for these tests are $\mathrm{CO}_{2}$ and BioSTAR (see above).

\section{Statistical methods used for data analysis}

For the interpretation of the model output data (model performance), the Wilmott index of agreement [24] (Equation 8) and the RMSE (root-mean-square error) (Equation 9) values have been calculated for all tested crops individually as well as all crops combined in one analysis (Table 1). For all crops combined, a linear regression and the corresponding $R^{2}$ value have been calculated (Figure 10). To see how the model reacts to inter-annual variations in climate, an inter-annual comparison of the observed and simulated yields has additionally been done for all crops combined and individually (Figures 1, 2, 3, 4, 5, 6, 7, 8, 9).

$$
\begin{aligned}
& d=1-\frac{\sum_{i=1}^{n}\left[\left(P_{i}-\bar{O}\right)-\left(O_{i}-\bar{O}\right)^{2}\right]}{\sum_{i=1}^{n}\left[\left(\left|P_{i}-\bar{O}\right|\right)+\left(\left|O_{i}-\bar{O}\right|\right)^{2}\right]} \\
& \text { RMSE }=\left\lfloor n^{-1} \sum_{i=1}^{n}\left(P_{i}-O_{i}\right)^{2}\right\rfloor^{-0.5},
\end{aligned}
$$

where $P_{i}$ is the instance of predicted value, $O_{i}$ is the instance of observed value, $\bar{O}$ is the mean of observed values, RMSE is the root-mean-square error, and $d$ is the Willmott index of agreement $(0=$ no agreement, $1=$ perfect agreement).

Table 2 Summary of model features

\begin{tabular}{ll}
\hline $\begin{array}{l}\text { Software } \\
\text { Data storage }\end{array}$ & Features \\
Multiple sites & Capability to process either individual sites or large datasets \\
Program type & Program runs from an executable Java file \\
Data organization & Soil, weather, crop, and result data are all kept in one database \\
Crop model & \\
Growth engines & User can choose between four growth engines and four ET T $_{0}$ methods \\
Time step & Daily or monthly climate data can be processed \\
Minimum data & If data availability is limited, the model can be run with only daily mean temperature \\
Perennial crops & Modeling of perennial crops like short rotation coppices or cup plant is possible \\
Soil model & Computation of soil water budget in a one-dimensional 2-m soil profile with decimeter layer increments using \\
van Genuchten soil texture parameters \\
Crop water stress
\end{tabular}




\section{Abbreviations}

APSIM: agricultural production simulator; AquaCrop: FAO crop model; $\mathrm{BBCH} /$ EC scale: growth scale of monocot and dicot plants; BioSTAR: Biomass Simulation Tool for Agricultural Resources; CERES: crop model in the DSSAT family; CROPGRO: crop model in the DSSAT family; CropSyst: cropping systems model; DSSAT: decision support system for agronomy transfer; $\mathrm{ET}_{\mathrm{a}}$ : actual evapotranspiration rate; $\mathrm{ET}_{0}$ : potential (reference) evapotranspiration rate; FAO: Food and Agriculture Organization; LINTUL: crop model in the Wageningen family; LWK: Landwirtschaftskammer (Niedersachsen); RMSE: root-mean-square error; RUE: radiation use efficiency; VPD: vapor pressure deficit of the air; WIA: Willmott index of agreement; WOFOST: crop model in the Wageningen family.

\section{Competing interests}

The author declares that he has no competing interests.

\section{Acknowledgements}

The development of the model BioSTAR has been made possible by funds of the Lower Saxony Ministry of Sciences and Culture (Germany). The research group responsible for developing the model is part of the interdisciplinary research project 'Sustainable use of bioenergy: bridging climate protection, nature conservation and society,' sub-project 2.2 'bioenergy potentials.

Received: 20 September 2013 Accepted: 6 December 2013

Published: 21 January 2014

\section{References}

1. BMWI-BMU: Energiekonzept für eine umweltschonende, zuverlässige und bezahlbare Energieversorgung. Berlin; 2010. http://www.iwo.de/fileadmin/ user_upload/Dateien/Standpunkte/Energiekonzept-2010.pdf.

2. FNR: Fachagentur für nachwachsende Rohstoffe. Basisdaten Bioenergie; 2011. http://mediathek.fnr.de/media/downloadable/files/samples/f/n/fnr_basisdaten_ 2012_web_neu.pdf.

3. Karpenstein-Machan M, Weber C: Energiepflanzenanbau für Biogasanlagen-Veränderungen in der Fruchtfolge und der Bewirtschaftung von Ackerflächen in Niedersachsen. Naturschutz und Landschaftsplanung. 2010, 42:312-320.

4. Ruppert $\mathrm{H}$ : Wege zum Bioenergiedorf-Leitfaden für eine eigenständige Wärme-und Stromversorgung auf Basis von Biomasse im ländlichen Raum. 3rd edition. Güstrow: FNR; 2010.

5. BiS-Project of the University of Goettingen: homepage (English). http://www. bioenergie.uni-goettingen.de/index.php?id=107.

6. Bouman BAM, van Keulen H, Van Laar HH, Rabbinge R: The 'School of de Wit' crop growth simulation models: a pedigree and historical overview. Agr Syst 1996, 52:171-198.

7. De Wit CT: Photosynthesis of Leaf Canopies, Agricultural Research Report 663. PUDOC: Wageningen; 1965.

8. Monteith $\mathrm{J}$ : Climate and the efficiency of crop production in Britain. Philos Translat Royal Soc 1977, 281:277-294.

9. Steduto $P$, Hsiao TC, Ferres E: On the conservative behavior of biomass water productivity. Irrig Sci 2007, 25:189-207.

10. Tanner CB, Sinclair TR: Efficient water use in crop production: research or re-search? In Limitations to Efficient Water Use in Crop Production. Madison: American Society of Agronomy; 1983.

11. Boote K, Loomis R: The prediction of canopy assimilation. In Modeling Photosynthesis-from Biochemistry to Canopy, CSSA Special Publication no.19. Madison: CSSA; 1991

12. Stöckle C, Donatelli M, Nelson R: CropSyst, a cropping systems simulation model. Eur J Agron 2003, 18:289-307.

13. Keating B, Carberry PS, Hammer GL, Probert ME, Robertson MJ, Holzworth D, Huth NI, Hargreaves JNG, Meinke H, Hochman Z, McLean G, Verburg K, Snow V, Dimes JP, Silburn M, Wang E, Brown S, Bristow KL, Asseng S, Chapman S, McCown RL, Freebairn DM, Smith CJ: An overview of APSIM a model designed for farming systems. Eur J Agron 2003, 18:267-288.

14. Jones JG, Porter C, Boote K, Batchelor W, Hunt L, Wilkens P, Singh U, Gijsman AJ, Ritchie JT: The DSSAT cropping system model. Eur J Agron 2003, 18:235-265.

15. Todorovic M, Albrizio R, Zivotic L, Abi MT, Stöckle C, Steduto P: Assesment of aqua crop, CropSyst, and WOFOST models in the simulation of sunflower growth under different water regimes. Agron J 2009, 101:508-521.
16. Steduto P, Hsiao TC, Ferres E: AquaCrop—the FAO crop model to simulate yield response to water: I: concepts and underlying principles. Agron J 2009, 101:426-437.

17. Bauböck R: GlS-gestützte Modellierung und Analyse von AgrarBiomassepotenzialen in Niedersachsen - Einführung in das Pflanzenmodell BioSTAR, PhD thesis. University of Göttingen; 2013. http://hdl.handle.net/ 11858/00-1735-0000-000E-OABB-9.

18. Workgroup BioSTAR: Cartography, GIS and remote sensing section. University of Goettingen: homepage (English). http://www.uni-goettingen.de/en/ 431252.html.

19. LWK: Energiepflanzen in Niedersachsen-Anbauhinweise und Wirtschaftlichkeit Landwirtschaftskammer Niedersachsen; 2010. http://www.ml.niedersachsen de/download/59388

20. Haferkorn U: Größen des Wasserhaushaltes verschiedener Böden unter landwirtschaftlicher Nutzung im klimatischen Grenzraum des Mitteldeutschen Trockengebietes-Ergebnisse der Lysimeterstation Brandis, PhD thesis. University of Göttingen; 2000. http://hdl.handle.net/11858/00-1735-0000-000D-F107-4.

21. Zenker T: Verdunstungswiderstände und Gras-Referenzverdunstung Lysimeteruntersuchungen Zum Penman-Monteith-Ansatz im Berliner Raum, Volume PhD thesis. TU Berlin: TU Berlin; 2003. http://nbn-resolving.de/urn/resolver. pl?urn:nbn:de:kobv:83-opus-6956.

22. DWW: Merkblätter zur Wasserwirtschaft - Ermittlung der Verdunstung von land- und Wasserflächen. Bonn: Heft 238/1996.

23. Eulenstein F, Olejnik J, Willms M, Schindler U, Chojnicki B, Meißner R: Mögliche Auswirkungen der Klimaveränderungen auf den Wasserhaushalt von Agrarlandschaften in Nord-Mitteleuropa. In Wasserwirtschaft. Wiesbaden: Springer-Vieweg; 2006.

24. Willmott CJ: Some comments on the evaluation of model performance. Bull Am Meteorol Soc 1982, 63:1309-1313.

\section{doi:10.1186/2190-4715-26-1}

Cite this article as: Bauböck: Simulating the yields of bioenergy and food crops with the crop modeling software BioSTAR: the carbon-based growth engine and the BioSTAR $\mathrm{ET}_{0}$ method. Environmental Sciences Europe 2014 26:1.

\section{Submit your manuscript to a SpringerOpen ${ }^{\circ}$ journal and benefit from:}

- Convenient online submission

- Rigorous peer review

- Immediate publication on acceptance

- Open access: articles freely available online

- High visibility within the field

- Retaining the copyright to your article

Submit your next manuscript at $>$ springeropen.com 